\title{
Changes in oral health over ten years amongst UK children aged $4-5$ years living in a deprived multiethnic area
}

\author{
R. Bedi, ${ }^{1}$ J. D. Lewsey, ${ }^{2}$ and M. S. Gilthorpe, ${ }^{3}$
}

Objective To examine the changes over a decade in caries experience amongst children aged 4-5 years living in a deprived multiethnic community in the United Kingdom.

Design Cross-sectional surveys.

Setting Schools and nurseries in the Old Trafford area,

Manchester, England, 1989, 1990, 1991 and 1998.

Main outcome measures Mean $\mathrm{dmft}$, oral cleanliness and proportion of children with rampant caries.

Results The unadjusted Odds Ratio for caries free children examined in 1998 compared with children examined prior to 1998 , was only significant amongst the white group. White children examined in 1998 were over three times more likely to be caries free than white children examined previously. South Asian children whose mothers were non English speaking examined in 1998 were almost twice as likely to have good/fair oral cleanliness than those examined prior to 1998. Moreover, South Asian children whose mothers were non-English speaking in 1998 were over three times more likely not to have rampant caries than their counterparts in the earlier years.

Conclusion There were significant improvements in caries and oral health amongst white children over the decade, and although less marked these were mirrored amongst South Asian children.

mprovements in prevention and the widespread use of fluoride 1 dentifices have made a significant positive impact on child oral health. However, dental caries still remains one of the most common diseases of childhood. Much is known about the occurrence of dental caries in the United Kingdom child population, and this information is primarily gained from two sources. First, the decennial surveys, since 1973, conducted under the auspices of the Office of Population Censuses and Surveys. ${ }^{1-3}$ Second, the regular surveys coordinated since 1985 by the British Association for the Study of Community Dentistry (BASCD). ${ }^{4}$ The caries experience has declined dramatically in the child population over the two decades, with the mean dmft of 5-year-old children in England and Wales falling by over 50 percent. ${ }^{1,2,5}$ However, little is known of the dental experience of minority ethnic children resident in the United Kingdom. ${ }^{5-6}$

The minority ethnic population has grown rapidly over the last 4 decades, but more recently the rate of growth now shows signs of

\footnotetext{
$1^{*}$ Professor and Head, ${ }^{2}$ Research Fellow, ${ }^{3}$ Senior Research Fellow, WHO Collaborating Centre for Oral Health, Disability and Culture, National Centre for Transcultural Oral Health, Eastman Dental Institute for Oral Health Care Sciences, University College London, 256 Gray's Inn Road, London WC1X $8 L D, U K$

${ }^{*}$ Correspondence to: $R$. Bedi

email:r.bedi@eastman.ucl.ac.uk

REFEREED PAPER

Received 19.07.99; accepted 17.02.00

(C) British Dental Journal 2000; 189: 88-92
}

slowing. The rapid growth of the major minority ethnic groups in the 1970s and 1980s were largely due to immigration from the New Commonwealth countries. ${ }^{7}$ The 1991 Census of England and Wales estimated that the minority ethnic community was almost 2.95 million or $6 \%$ of the total population. It is estimated that the relative proportional increase of these groups will be primarily due to their relative younger age profile and larger family size compared to the white community. ${ }^{7}$ Approximately $56 \%$ of these were identified as being of Indian extraction, while $30 \%$ were black. ${ }^{8}$ Traditionally, in the dental literature, ethnic groups in the UK have been classified as white, Asian, black or other even though it was recognized that significant differences exist within these groups in terms of socio-economic status, lifestyle, genetic predisposition, disease patterns and mortality levels. ${ }^{6}$

The report of the 1993 children's survey highlighted independent variables, which were considered to have possible influences on caries experience. ${ }^{3}$ The influence of ethnic background was not considered since no records were kept on the ethnic background of the sample children. ${ }^{3}$ However, from a number of small scale studies a common pattern is developing which shows that among schoolchildren, caries experience in the primary dentition is significantly higher in the Asian population than in the white group. ${ }^{5}$ The mean dmft scores in Asian children are recorded as 1.5 to twice as high as those in white children. ${ }^{5}$

It is still not clear whether ethnicity or social deprivation is the key variable when attempting to understand the differences in oral health. Oral health research has all too often indiscriminately used broad ethnic classifications e.g. Asian and failed to consider important social deprivation variables. This approach has diverted attention from the more fundamental issues such as low income and social class differences, which are well documented factors, which influence dental inequalities. Social deprivation in ethnic terms, may be better defined in terms of indirect variables such as ability to speak English, rather than the more established ones, e.g. unemployment. ${ }^{9}$

The aim of this study was to examine the changes over a decade in caries experience amongst children aged $4-5$ years living in a deprived multiethnic community in the United Kingdom.

\section{Method}

This study took place in the city of Manchester, north England, within the inner city area of Old Trafford. This district of the city was chosen because of its large minority ethnic population, combined with its high experience of socioeconomic deprivation. Children from several schools in the area were surveyed over three years between 1989 and 1991, and the findings and methodology of these surveys have been previously reported elsewhere. ${ }^{10-11}$ In summary, a single calibrated examiner (RB) undertook all dental examinations. An anglepoise lamp provided the illumination and compressed air was available. Only primary teeth were examined. The oral cleanliness was measured using the 
categories advocated by James et al. ${ }^{12}$ No radiographs were taken and $10 \%$ of the schoolchildren were chosen at random and reexamined at the end of the survey.

A dental survey was undertaken in 1998, using the same protocol and schools, to examine changes in the overall caries experience and changes in the oral cleanliness differentials between different ethnic groups. All schools in the area participated in each year of the study.

In total, this study evaluated the oral health status of 883 school children who were aged between 4 years 0 months and 5 years 11 months at the beginning of each of four school years (mean age: 5 years 6 months). Table 1 gives the frequencies of children by demographic characteristics.

Multiple regression analysis was used to explore the potential effects of age, gender, ethnic background and year of examination on caries experience, oral cleanliness and rampant caries. As it was hypothesised that the mother's command of English might have an impact on their children's oral health experiences, ethnic group was further classified amongst the South Asian children (the largest group within the study) according to their mother's ability to speak English. ${ }^{10}$

The distributional properties of $\mathrm{dmft}$ were initially examined to confirm that the sample adopted an underlying Normal distribution. The percentage distributions of $\mathrm{dmft}$ including and excluding caries free children are shown in Figures 1 and 2, respectively. It is clear from these figures that $\mathrm{dmft}$ did not follow a Norma distribution. Thus, it would have been erroneous to make inferences on dmft for different groups using procedures reliant on normality in the response (such as $t$-testing and simple regression). It was therefore decided to employ a separate regression analysis for only those children who were carious $(\mathrm{dmft} \neq 0)$ adopting a Poisson distribution. ${ }^{13}$ Children were also analysed employing logistic regression with the binary response caries free and carious. The chi-squared test for trend was employed to detect any time effects of year of study.

Logistic regression was also used to explore oral cleanliness (good/fair vs. poor) and rampant caries. The latter was defined in two ways. Firstly, rampant caries was defined as present for children where two maxillary incisors were decayed, missing (due to decay), or filled (due to decay), or any combination of these. Secondly, rampant caries was defined as present for children with a dmft score greater than or equal to eight. All logistic regression analyses yielded odds ratios (ORs) where account had been made of the influence of all factors simultaneously. Such ORs are referred to as adjusted ORs because other covariate effects have been accounted for. Interac-
Table 1 Frequency and percentage of children by demographic characteristics

\begin{tabular}{|c|c|c|c|}
\hline & & equency & Percentage (\%) \\
\hline \multicolumn{4}{|l|}{ Age group } \\
\hline & $\leq$ mean $(5.5 \mathrm{yrs})$ & 507 & 57.4 \\
\hline & $>$ mean & 376 & 42.6 \\
\hline \multicolumn{4}{|l|}{ Gender } \\
\hline & Girls & 436 & 49.4 \\
\hline & Boys & 447 & 50.6 \\
\hline \multicolumn{4}{|l|}{ Ethnic Group 1} \\
\hline & $\begin{array}{l}\text { South Asian } \\
\text { NESM }^{2}\end{array}$ & 187 & 21.2 \\
\hline & $\begin{array}{l}\text { South Asian } \\
\text { ESM }^{3}\end{array}$ & 313 & 35.4 \\
\hline & White & 213 & 24.1 \\
\hline & Afro-Caribbean & 158 & 17.9 \\
\hline
\end{tabular}

${ }_{1}^{1}$ Twelve children could not be assigned to the above ethnic group categories 2 South Asian children whose mothers are non-English speaking

${ }^{3}$ South Asian children whose mothers are English speaking

tions between ethnic group and year were also sought through regression analyses, but this led to computational problems due to small numbers in many of the resulting categories.

Consequently, only unadjusted odds ratios (ORs) could be evaluated comparing changes over time by each ethnic group (unadjusted because they were calculated outwith a modelling process and thus did not take into account the influence of other covariate effects). The unadjusted odds of each binary outcome in 1998 was compared with the unadjusted odds for those children examined prior to 1998 , for each ethnic group.

\section{Results}

All the primary and nursery schools in the Old Trafford area, participated in each survey. The residential area for the schools has remained over the study period to be classified as a deprived urban priority area, with the majority of families being from a low social economic background. The intra-operator reproducibility for each survey was always greater than $\kappa=0.9$ for both dental caries and oral cleanliness.

Table 2 Regression analysis using age, gender, ethnicity and year of survey for each major oral health outcome

\begin{tabular}{|c|c|c|c|c|c|}
\hline \multirow[b]{2}{*}{ Covariates } & \multicolumn{2}{|l|}{ Poisson Regression } & \multicolumn{2}{|c|}{ Logistic Regression Odd Ratios } & \multirow[b]{2}{*}{ Rampant caries $(\mathrm{dmft} \geq 8)$} \\
\hline & dmft (Carious) & Caries free & Oral cleanliness & Rampant caries (upper incisors) & \\
\hline $\begin{array}{l}\text { Baseline } \\
\text { Older than average } \\
\text { Male child }\end{array}$ & $\begin{array}{l}3.877 \\
0.645^{\dagger} \\
0.195\end{array}$ & $\begin{array}{r}45.0 \% \\
0.812 \\
0.804\end{array}$ & $\begin{array}{l}75.2 \% \\
0.762 \\
0.560^{\ddagger}\end{array}$ & $\begin{array}{c}14.4 \% \\
0.980 \\
1.231\end{array}$ & $\begin{array}{l}12.8 \% \\
1.465^{\dagger} \\
1.121\end{array}$ \\
\hline \multicolumn{6}{|l|}{ Ethnic Group $¥$} \\
\hline $\begin{array}{l}\text { Afro-Caribbean } \\
\text { South Asian NESM } \\
\text { South Asian ESM }\end{array}$ & $\begin{array}{c}-0.848 \\
1.156^{\dagger} \\
0.126\end{array}$ & $\begin{array}{l}1.530^{\dagger} \\
0.531^{\ddagger} \\
0.695\end{array}$ & $\begin{array}{l}2.679 \ddagger \\
0.312^{\ddagger} \\
0.603^{\ddagger}\end{array}$ & $\begin{array}{l}0.359^{\ddagger} \\
2.230^{\dagger} \\
1.250\end{array}$ & $\begin{array}{l}0.483^{\dagger} \\
1.870^{\dagger} \\
0.996\end{array}$ \\
\hline \multicolumn{6}{|c|}{ Year of examination $\S$} \\
\hline $\begin{array}{l}1990 \\
1991 \\
1998\end{array}$ & $\begin{array}{r}0.399 \\
0.027 \\
-0.042\end{array}$ & $\begin{array}{l}1.052 \\
1.298 \\
1.567^{\dagger}\end{array}$ & $\begin{array}{l}1.314 \\
2.321 \ddagger \\
3.122^{\ddagger}\end{array}$ & $\begin{array}{l}2.087^{\dagger} \\
1.446 \\
0.941\end{array}$ & $\begin{array}{l}1.353 \\
1.237 \\
0.999\end{array}$ \\
\hline
\end{tabular}

$t_{\text {significant at the } 95 \% \text { level }(P<0.05)}$

Isignificant at the $99 \%$ level $(P<0.01)$

¥ white group is baseline

$\S 1989$ is baseline 


Table 3 Ethnic background and major oral outcomes
outcomes
\begin{tabular}{lccccc}
\hline Ethnic group & Number of children (\%) & Caries free & Oral cleanliness & Rampant caries (upper incisors) & Rampant caries (dmft $\geq 8$ ) \\
\hline White & $213(25 \%)$ & $3.17^{\dagger}$ & 3.17 & 1.71 & 0.77 \\
Afro-Caribbean & $158(18 \%)$ & 1.84 & $\#$ & $\S$ & $\S$ \\
South Asian NESM & $187(21 \%)$ & 1.96 & $1.88^{\dagger}$ & 1.75 & $3.09 \dagger$ \\
South Asian ESM & $313(36 \%)$ & 0.88 & 2.10 & 1.24 & 0.82
\end{tabular}

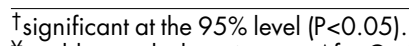

$¥$ unable to calculate since no Afro-Caribbean child had poor oral cleanliness in 1998 .

$\S$ unable to calculate since no Afro-Caribbean child rampant caries of either definition in 1998.

The results of the regression analyses are shown in Table 2, and unadjusted Odds Ratios (ORs) in Table 3. It should be noted that the 'other' minority ethnic group $(n=12)$ were not included in the analyses. The Poisson model in Table 2 indicates how each covariate affected the mean $\mathrm{dmft}$ score of those children who are carious $(\mathrm{dmft} \neq 0)$. The remaining logistic regression models in Table 2 reveal, for each covariate in turn, the adjusted ORs for each outcome.

\section{Caries experience}

As expected, for children older than average, there was an associated increase in the $\mathrm{dmft}$ scale when compared with those children of average and younger age (Table 2). There were no significant gender differences. South Asian children whose mothers were non-English speaking (NESM) were associated with a greater level of $\mathrm{dmft}$ than their white counterparts. The results also suggest that there was a general improvement in caries experience between 1989 and 1998. There was a significant trend between decreasing proportion of children with caries and increasing year of study.

The probability of being caries free for the Afro-Caribbean group was significantly greater than the probability of being caries free for the white group. An effect of similar magnitude was observed for the South Asian non-English speaking mother (NESM) group, although occurring in the opposite direction. That is, the probability of being caries free for the South Asian NESM group was significantly reduced compared with the probability of being caries free for the white group. There was also evidence to show that the probability of being caries free in 1998 was significantly greater than the respective probability in 1989 .

The unadjusted OR for caries free children examined in 1998 compared with children examined prior to 1998 was only significant amongst the white group (Table 3 ). White children examined in 1998 were over three times more likely to be caries free than white children examined previously. Although an insignificant result, it is worth noting that the estimate associated with the South Asian ESM group indicates a reduced chance of being caries free in 1998.

Perhaps the most prominent observation is associated with the South Asian NESM group. Not only were this group more likely to be carious than the white group, but they also had higher associated levels of $\mathrm{dmft}$.

\section{Oral cleanliness status}

The probability of boys having poor oral cleanliness was significantly greater than the respective probability for girls (Table 2). The Afro-Caribbean group were significantly more likely to have good/fair oral cleanliness than the white group. Both South Asian groups were significantly less likely to have good/fair oral cleanliness than the white group. The probabilities of good/fair oral cleanliness for children examined in 1998 and 1991 were significantly greater than the respective probability for children examined in 1989. The probabilities for examination years 1989 and 1990 were not statistically different. Furthermore, the results suggest that there was a general improvement in oral cleanliness associated with year of study. Again, there was a significant decreasing proportion of children with poor oral cleanliness against increasing year of study.

Table 4 Descriptives of main oral outcomes categorised by ethnicity and year of examination

\begin{tabular}{|c|c|c|c|c|c|c|c|c|}
\hline & \multicolumn{4}{|c|}{1989} & \multicolumn{4}{|c|}{1990} \\
\hline & $\begin{array}{c}\text { Median } \\
\left(I Q R^{\dagger}\right) \mathrm{dmft}\end{array}$ & Caries free $(\%)$ & $\begin{array}{c}\text { Median } \\
\text { (IQR') dmft } \\
\text { (carious only) }\end{array}$ & $\begin{array}{c}\text { Oral } \\
\text { cleanliness } \ddagger(\%)\end{array}$ & $\begin{array}{c}\text { Median } \\
\left(\mid Q^{\dagger}\right) \mathrm{dmft}\end{array}$ & Caries free $(\%)$ & $\begin{array}{c}\text { Median } \\
\left(\mid R^{\dagger}\right) \mathrm{dmft} \\
\text { (carious only) }\end{array}$ & $\begin{array}{c}\text { Oral } \\
\text { cleanliness } \\
\end{array}(\%)$ \\
\hline South Asian NESM & $3.0(0-8)$ & 25.8 & $6.0(3-10.25)$ & 45.2 & $5.0(0-9)$ & 32.1 & $8.0(5-11.75)$ & 41.5 \\
\hline South Asian ESM & $2.0(0-6.75)$ & 31.0 & $4.0(2-8.25)$ & 48.8 & $2.0(0-6)$ & 37.9 & $5.0(3-7)$ & 62.1 \\
\hline White & $2.0(0-6)$ & 36.5 & $4.5(2-7.75)$ & 61.9 & $1.5(0-6)$ & 40.2 & $5.0(2-8.5)$ & 76.8 \\
\hline \multirow[t]{3}{*}{ Afro-Caribbean } & $0(0-4)$ & 54.9 & $5.0(2-6)$ & 88.2 & $1.0(0-4)$ & 43.1 & $3.0(1-6)$ & 84.3 \\
\hline & \multicolumn{4}{|c|}{1991} & \multicolumn{4}{|c|}{1998} \\
\hline & $\begin{array}{c}\text { Median } \\
\left(\mid R^{\dagger}\right) d m f t\end{array}$ & Caries free (\%) & $\begin{array}{c}\text { Median } \\
\left(\mid \mathrm{QR}^{\dagger}\right) \mathrm{dmft} \\
\text { (carious only) }\end{array}$ & $\begin{array}{c}\text { Oral } \\
\text { cleanliness } \ddagger(\%)\end{array}$ & $\begin{array}{c}\text { Median } \\
\left(I Q R^{\dagger}\right) d m f t\end{array}$ & Caries free $(\%)$ & $\begin{array}{c}\text { Median } \\
\left(\mid Q R^{\dagger}\right) \mathrm{dmft} \\
(\text { carious only) }\end{array}$ & $\begin{array}{c}\text { Oral } \\
\text { cleanliness }{ }^{\ddagger}(\%)\end{array}$ \\
\hline South Asian NESM & $4.0(1-9.5)$ & 22.0 & $4.5(2-10)$ & 53.7 & $2.0(0-6)$ & 41.9 & $4.0(2-6.5)$ & 64.5 \\
\hline South Asian ESM & $1.5(0-5)$ & 44.3 & $4.0(2-8)$ & 81.4 & $3.0(0-6)$ & 34.4 & $5.0(3-8)$ & 76.3 \\
\hline White & $1.0(0-4.75)$ & 45.0 & $3.5(2-7.5)$ & 80.0 & $0(0-3.75)$ & 67.9 & $9.0(3.5-10.5)$ & 89.3 \\
\hline Afro-Caribbean & $0(0-4)$ & 60.5 & $4.0(3-9)$ & 86.8 & $0(0-1)$ & 66.7 & $2.0(1-3.25)$ & 100.0 \\
\hline
\end{tabular}

$\dagger_{I Q R}=$ Inter Quartile Range

$\ddagger$ Percentage with good/fair oral cleanliness 


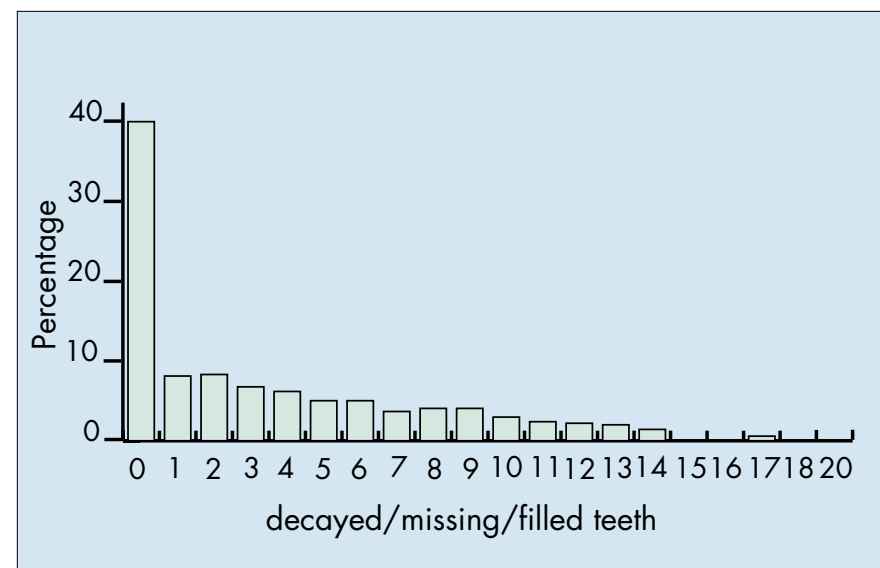

Fig. 1 Percentage distribution of $d m f t$ (including $d m f t=0$ )

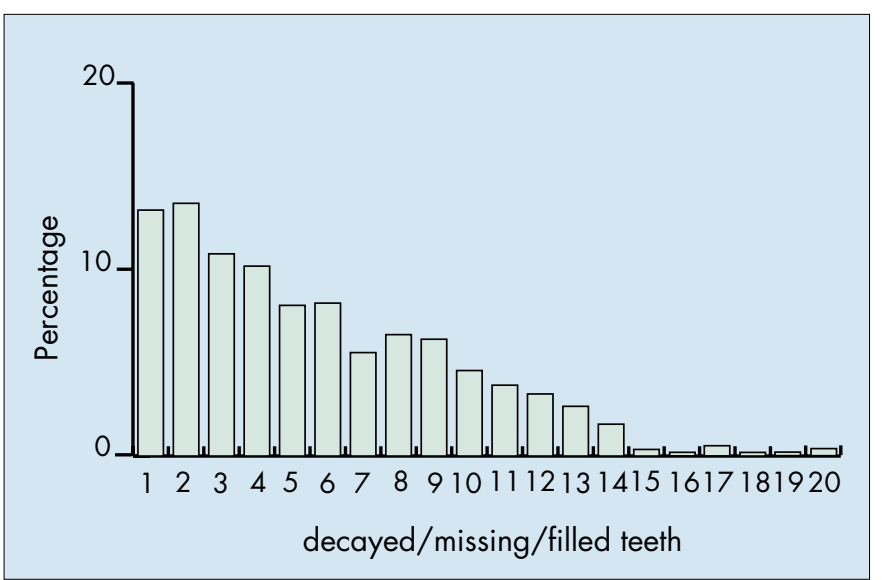

Fig. 2 Percentage distribution of $\mathbf{d m f t}$ (including $d m f t \neq 0$ )
There was a significant difference in the unadjusted ORs amongst only the South Asian NESM group (Table 3). South Asian NESM children examined in 1998 were almost twice as likely to have good/fair oral cleanliness than South Asian NESM children examined prior to 1998. The ORs for white and South Asian ESM group just failed to reach significance, though it could be cautiously argued that the oral cleanliness status of children from these groups in 1998 is better, in general, than for previous examination years. The same argument could be applied to the Afro-Caribbean group since prior to $199814 \%$ of children had poor oral cleanliness, yet in 1998 all eighteen Afro-Caribbean children had good/fair oral cleanliness.

Table 4 provides a summary of the main oral outcomes categorised by ethnicity and year of examination.

\section{Rampant caries}

Age was a significant predictor of rampant caries (Table 2) when defined as $\mathrm{dmft} \geq 8$ but not when defined using maxillary incisors. For either definition, the probability of having rampant caries was significantly reduced for the Afro-Caribbean group when compared with the white group. Conversely, the probability of having rampant caries was significantly increased for the South Asian NESM group when compared with the white group.

Year of examination appeared to be only an influence when the first definition of rampant caries was employed. The probability of having rampant caries in 1990 was significantly greater than the respective probability for 1989 . The year of examination covariates in both models suggested a possible trend but when formally assessed no significant associations were found.

Only the $\mathrm{dmft} \geq 8$ definition of rampant caries gave rise to a significant unadjusted OR (Table 3). South Asian NESM children in 1998 were over three times more likely not to have rampant caries than their counterparts in the earlier years. This is noteworthy because although the results of Table 2 indicate that South Asian NESM children were more likely to have rampant caries than white children, the results of Table 3 shows that the prevalence is perhaps lessening. All other unadjusted results are insignificant. However, the estimates for the ORs for white and South Asian ESM groups differ in terms of their direction with respect to the definition of rampant caries. For the first definition, the results indicate that the odds of not having rampant caries have increased (1998 compared with previous years); whilst, for the second definition the corresponding odds have actually decreased.

\section{Discussion}

The comparisons over the decade are interesting but the 1990s have seen significant government policies to address inner city decline and investment in urban regeneration. The previously published data on Old Trafford children have varied, in that the first published study was undertaken in 1987 and 1988 involving only 5year old children. ${ }^{10}$ In this study an additional school was included which was subsequently closed. The study in 1989 comparing Old Trafford children with those in Greater Glasgow, examined 5 and 6year old children. ${ }^{11}$ In both the above studies, younger children were examined but excluded from the analysis and reports, ${ }^{10-11}$ and in this study the data was re-examined for all the years studied and just included $4-5$-year olds.

These results illustrate how separating the outcome of caries experience into two component parts is more powerful than analysing the complete $\mathrm{dmft}$ scale as a whole. For example, it can be seen that age was a clear predictor of the amount of dmft present, but it did not have any significant influence on whether a child was carious or not. Furthermore, the Afro-Caribbean group was at less risk of being carious than the white group, but the level of caries for the two groups was not significantly different for children who were carious. Similarly, although there is evidence to suggest that the chance of being caries free increased (1998 compared with 1989), the caries levels amongst children with caries were not significantly different for any study year. It is important to note that these findings would have been missed if only a single approach for caries experience analysis had been adopted.

The chosen regression analysis is superior to a non-parametric approach because the effects of age, gender, ethnicity and year of examination can be measured simultaneously, giving rise to estimates that take into account the influence of other effects in the modelling process. Moreover, by separating the response into two parts it can be determined (separately) which factors influence whether or not caries was present, and those factors which influenced the amount of caries present. Unfortunately there were insufficient numbers to apply a similar methodology incorporating interactions between ethnic group and year of study. Unadjusted ORs could not account for all other factors simultaneously. Nevertheless, unadjusted ORs provided a valuable insight into the changing patterns of oral health amongst children from different minority ethnic groups resident in a deprived area.

Results suggested that there was a change in most outcomes associated with year of study. The use of the year covariate could not confirm this alone, and it was necessary to evaluate trend using the $\chi^{2}$ test for trend. However, it would have been erroneous to fit a continuous year-of-study variable, as there were only four time points. The assumption that change in any outcome was linear over time would be further erroneous, since there have been significant changes in the provision of dental care to children throughout the study period e.g. capitation payments. ${ }^{14}$ Such changes might have 
yielded a moderate but sudden shift in the oral health of children of similar ages to those in this study.

Overall, the analyses reveal that there were improvements in the general oral health experiences of children aged 4-5 years resident in a deprived area. Levels of caries $(\mathrm{dmft} \neq 0)$ reduced and the proportion of caries free children increased over the ten-year study period. Oral cleanliness increased and rampant caries (defined by upper incisors) declined.

The analysis also revealed that there were many ethnic group differences in the oral health experiences of Old Trafford school children over the decade (Table 2). As reported previously, AfroCaribbean children generally faired better than white children, whilst South Asian children experienced more caries, were less likely to be caries free and had greater probability of poor oral cleanliness and rampant caries. However, this study indicates that improvements in caries and oral cleanliness amongst white children, whilst mirrored amongst South Asian children, were less marked (Table 3). However, South Asian children whose mothers were non-English speaking in 1998 were over three times less likely to have rampant caries than their counterparts in the earlier years.

From these analyses alone it is impossible to ascertain whether the observed trends will be sustained or merely a product of chance sampling. It would be ideal to gather more data in order to correctly map out changes in the oral health experience of children from different ethnic groups resident in deprived areas. It is hoped that the same area will be surveyed at least once more to clarify this position. In the meantime, there would appear to remain considerable diversity in the general oral health by ethnic group, and in terms of caries and oral cleanliness, this inequality does not appear to be reducing.
The authors wish to thank all the schools and nurseries who participated in the project. A special thanks goes to Mrs. M Ashton who supported and scribed all the surveys with enthusiasm and dedication. The help and support of the senior community dental staff in Old Trafford over the decade is appreciated and acknowledged.

1 Todd J E, Dodd T. Children's Dental Health in the United Kingdom 1983. London: HMSO, 1985.

2 O’Brien M. Children's Dental Health in the United Kingdom 1993. London: OPCS, 1994.

3 Downer M C. The changing pattern of dental disease over 50 years. $\mathrm{Br}$ Dent J 1998; 185: 36-41.

4 Nugent Z J, Pitts N B. Patterns of change and results overview 1985/61995/6 from the British Association for the Study of Community Dentistry (BASCD) coordinated National Health Service surveys of caries prevalence. Community Dent Health 1997; 14 (Suppl.): 30-54.

5 Downer M C, Bedi R, Holloway P J. Dental caries - epidemiology in the UK. In Oral Health - diet and other factors. British Nutrition Foundation. Elsevier Science B.V. Amsterdam, 1999.

6 Bedi R, Uppal R D K. The oral health of minority ethnic communities in the United Kingdom. Br Dent J 1995; 179: 421-425.

7 Office of Population Census And Surveys. County Monitors. London: OPCS, 1992.

8 Balarajan R, Raleigh V S. The ethnic populations of England and Wales: the 1991 census. Health Trends 1992; 24: 113-116.

9 Senior P A, Bhopal R. Ethnicity as a variable in epidemiological research. Br Med J 1994; 309: 327-330.

10 Bedi R. Ethnic indicators of dental health for young Asian school children resident in areas of multiple deprivation. Br Dent J 1989; 166: 331-334.

11 Bedi R, Elton R A. Dental caries experience and oral cleanliness of Asian and White Caucasian children aged five and six years attending primary schools in Glasgow and Trafford, United Kingdom. Community Dent Health 1991; 8: 17-23.

12 James PMC, Jackson D, Slack GL, Lawton FE. Gingival health and dental cleanliness in English schoolchildren. Arch Oral Biol 1960; 3: 57-66.

13 McCullagh P, Nelder J A. Generalized Linear Models. London : Chapman and Hall, 1989.

14. White D, Anderson R J. Children's dental health under the capitation scheme. Community Dent Health 1996; 13: 21-48. 